\title{
A Discrete Model of the Expected Loss for Catastrophe Insurance in Natural Disasters Chongfu Huang ${ }^{1,2} \quad$ Xing Shi ${ }^{2.3}$ \\ ${ }^{1}$ State Key Laboratory of Earth Surface Processes and Resources Ecology (Beijing Normal University) Beijing 100875, China, hchongfu@bnu.edu.cn \\ ${ }^{2}$ Bank of China Insurance, Beijing 100818, China \\ ${ }^{3}$ Academy of Disaster Reduction and Emergency Management, Ministry of Civil Affairs \& Ministry of Education the Peoples' Republic of China, Beijing Normal University, Beijing 100875, China
}

\begin{abstract}
The traditional actuarial model of catastrophe insurance is too theoretical. In many cases, it is of no avail. In this paper, we suggest a discrete model of catastrophe insurance to calculate the expected losses. We successfully applied to calculate the premium rate of the typhoon in Fujian Province, China. In this model, we use the conditional probability distribution of catastrophic events given a lower-catastrophe and the probability distribution of the catastrophe times to express randomness of catastrophe, use the matrix showing the damage ratio of a single insured object and the matrix showing the insurance loss to express the relationship between catastrophe and economic loss, and use the discrete probability distribution and catastrophe losses and above the relationship to calculate the expected loss. When we use the model to calculate the premium rate, we consider adjustment factors and insurance amount, and partly apply the general actuarial model. Research shows that the model versatility, easy operation, the results more reliable.
\end{abstract}

Keywords: Typhoon, insurance, actuarial, Fujian, house.

\section{自然灾害巨灾保险中估计期望损失的一个离散化模型 \\ 黄崇福 ${ }^{1,3}$ 石兴 $^{2,3}$ \\ 1.北京师范大学地表过程与资源生态国家重点实验室，北京 100875}

2. 中银保险有限公司，北京 100818

3. 北京师范大学, 民政部/教育部减灾与应急管理研究院，北京 100875

摘要：传统的巨灾保险费率精算模型过于理论化, 许多时候无法使用。本文建议了一个计算期望损失的 巨灾保险离散化模型，并成功应用于中国福建省的台风保险费率。在该模型中，我们用大于等于某级巨灾的巨 灾条件概率分布和它们出现次数的概率分布来表达巨灾的随机性, 以巨灾中单体标的破坏比矩阵和破坏程度与 保险损失矩阵来表达巨灾与经济损失的关系，并用离散概率分布和巨灾与经济损失的离散关系来计算期望损失 值。在用该模型计算费率, 我们考虑了费率调整因子和保险金额, 并部分用到了通用精算模型等。研究表明, 该模型通用性强, 易操作, 结果较为可靠。

关键词：台风，保险，精算，福建，住宅

\section{1. 引言}

自然灾害巨灾保险是以某一保险条款为基础, 以触发约定标准的巨灾风险为主要保险责任，在约 定的自然灾害巨灾保险区划范围内，对特定的保险 标的，依据法规，建立巨灾风险共保体，并对巨灾 保险所做出的制度性安排。

巨灾的内涵是指某一次灾害发生后，发生地已 无力控制灾害所造成的破坏，必须借助外部力量进
行处置。例如，风速达到每秒 20.8-24.4 米的 9 级 以上的台风，会形成巨灾。

巨灾风险，必须进行共保。亦即是在确定的巨 灾保险区划内，所有利益做关方组成命运共同体。 通常的做法是，政府财政发起出资组建共保体，成 为最后的财务风险承担者。国内所有保险人，乃至 再保险人出资参加共保体, 并组成管理层受托经营 管理。被保险人参与分担风险, 比例自保一部分。 这种由政府、保险人和被保险人组成的新型共保 
体，使再大的巨灾风险也得以最为广泛地分担，有 助于实现巨灾风险的可保性。

巨灾保险能否实施, 依赖于巨灾保险费率精算 模型是否有效。

\section{2. 传统巨灾保险期望损失模型}

传统的巨灾保险费率精算由3部分组成：巨灾事 件分析、经济损失估计和计算保险人损失期望值。

\section{1 巨灾事件分析}

某一地区内，一定时间内发生某种巨灾事件主 要取决于自然灾害规律的作用和周边地区自然环 境, 其一次损失程度的大小主要取决于自然灾害类 型及其风险强度和发生该自然灾害事件所在地区域 的建筑物分布和社会经济状况。在一定时间内, 一 个地域内的自然环境及其建筑物分布具有一定的稳 定性, 因此, 我们可用一个地区的位置来代表它 们, 设为 $L$ 。在保险实践中, 有的用邮编来表示地 区的划分，有的用经纬度来划分地区。

地点 $L$ 发生某一程度的巨灾事件具有一定的随 机性, 为了研究巨灾事件对该地点造成的社会损 失, 选取与该巨灾事件导致的经济损失程度具有良 好相关性的物理特性的组合, 即描叙巨灾事件强度 的变量的组合, 记作 $X_{L}$, 它是一个随机变量族, 设其取值空间为 $\Omega_{L}$ 。如果把一次巨灾风险所带来 的衍生灾害也算在同一次的话, 我们可以近似假设 每次灾害的 $X_{L}$ 是独立同分布的。根据自然灾害发 生的机制, 结合地点 $L$ 及周围的自然环境特性, 参 考历史数据和经验, 我们可以设定 $X_{L}$ 的概率密度函 数为 $p_{L}(x), x$ 是 $\Omega_{L}$ 中的元素。

同样, 地点 $L$ 在时间 $t$ (以年为单位) 内发生该 巨灾事件的次数为随机过程, 通常假设为由式 (1) 所示的泊松过程 $N_{L}(t)$ 。它描述了对任意固定的时 间段 $t$, 在这一时间段内随机事件发生 $k$ 次的概率。 参数 $\lambda_{L}$ 为泊松过程的强度。在 $t$ 时间段的期望值由式 （2）计算。特别地, 在时间段为一年的情况下, 由 式 (3) 知, 在地点所面临某一巨灾风险可能发生 的期望次数正好为 $\lambda_{L}$ 。

$$
\begin{gathered}
P\left(N_{L}(t)=k\right)=\frac{(\lambda t)^{k}}{k !} e^{-\lambda t}, \quad k=0,1,2 \ldots \\
E\left(N_{L}(t)\right)=\lambda_{L} \times t \\
E\left(N_{L}(1)\right)=\lambda_{L}
\end{gathered}
$$

\section{2 经济损失估计}

巨灾事件发生时, 影响经济损失程度大小的因 素虽然较多, 归纳起来有四大类: 该巨灾事件的物 理性质, 主要是其强度信息; 风险暴露单位数量价 值及其分布; 建筑物的抗灾能力, 即建筑物抗灾级 别和结构特性; 以及社会减灾能力。显然前两者与 经济损失是正向关系, 后两者与经济损失呈反向关 系。

根据历史数据和经验, 我们可以采用模型来预 测某一灾害发生时的损失。对于地点 $L$, 我们假设 单次巨灾事件所造成的经济损失为:

$$
y_{L}=G\left(X_{L}, S_{L}, M_{L}, D_{L}\right)
$$

其中, $S_{L} 、 M_{L} 、 D_{L}$ 分别表示地点 $L$ 的抗灾能力、 经济价值分布和社会减灾能力信息。

\section{3 计算保险人损失期望值}

当地点 $L$ 的经济损失确定了后, 保险人的损失 主要受以下因素的影响: 保险责任范围、保险金额 的共保比例、免赔额等保险条件。为了简单起见, 我们用 $I_{L}$ 来表示地点 $L$ 的保险相关情况。

设 $z_{L}$ 表示地点 $L$ 发生一次巨灾事件所造成保险 人的损失, 根据 $y_{L}$ 和 $I_{L}$, 通常作如下假设:

$$
z_{L}=H\left(y_{L}, I_{L}\right)=H\left(G\left(x, S_{L}, M_{L}, D_{L}\right), I_{L}\right)
$$

则地点 $L$ 面临单次巨灾事件时，保险人的期望损失 为:

$$
E\left(z_{L}\right)=\int_{\Omega_{L}} H\left(G\left(x, S_{L}, M_{L}, D_{L}\right), I_{L}\right) \times p_{L}(x) d x
$$

设 $v_{L}(t)$ 表示地点 $L$ 在时间 $t$ 内由单一巨灾事件 所造成保险人的总损失, 则

$$
v_{L}(t)=\sum_{k=1}^{N_{L}(t)} z_{L}
$$

这里的 $k$ 是指巨灾事件发生的次数。

同理, 地点 $L$ 在时间 $t$ 内由单一巨灾事件造成 保险人的总期望损失为:

$$
\begin{aligned}
& E\left(v_{L}(t)\right)=E\left(N_{L}(t)\right) \times E\left(z_{L}\right) \\
& =\lambda_{L} \times t \times \int_{\Omega_{L}} H\left(G\left(x, S_{L}, M_{L}, D_{L}\right), I_{L}\right) \times p_{L}(x) d x
\end{aligned}
$$

由此可得地点 $L$ 在一年内由该巨灾事件造成保险人 的总期望损失 $E$ 为 ${ }^{[1]}$ :

$$
E=\lambda_{L} \times \int_{\Omega_{L}} H\left(G\left(x, S_{L}, M_{L}, D_{L}\right), I_{L}\right) \times p_{L}(x) d x
$$


显然, 式 (9) 是一个理论模型, 函数表达式 $G$ 和 $H$ 均不易确定。

\section{3. 离散化的巨灾保险期望损失模型}

由于传统模型中一系列函数的表达式不易确 定, 用少量巨灾样本估计出的有关参数其可靠性也 不高。所以, 在许多情况下, 传统模型的理论意义 大于实际意义。本文根据巨灾风险的特点, 提出离 散化的巨灾保险期望损失模型，使理论模型过渡到 实用模型。

离散模型涉及两个主要的定义域, 一个是巨灾 等级的定义域; 另一个是财产破坏程度的定义域。
例如, 大于 9 级的台风, 其风力等级查表 1 可 知。而住宅破坏程度的定义域, 可由表2给出。台风 的定义域记为W (用 “Wind” 的第一个字母), 破 坏定义域记为D（用 “Damage的第一个字母）。它 们可分别用式（10）和（11）表之。

$W=\left\{w_{1}, w_{2}, w_{3}, w_{4}, w_{5}\right\}$

$=\{9$ 级风, 10 级风, 11 级风, 12 级风,13-17 级风 $\}$

$D=\left\{d_{1}, d_{2}, d_{3}, d_{4}, d_{5}\right\}$

$=\{$ 基本完好,轻微破坏,中等破坏,严重破坏,完全破坏 $\}$

表1. 风力等级表

\begin{tabular}{|c|c|c|c|c|}
\hline \multirow{2}{*}{ 风力级数 } & \multirow{2}{*}{ 名称 } & \multirow{2}{*}{ 陆地地面征象 } & \multicolumn{2}{|l|}{ 风速 } \\
\hline & & & (米/秒) & (公里/小时) \\
\hline 0 & 静稳 & 静, 烟直上 & $0-0.2$ & $<1$ \\
\hline 1 & 软风 & 烟能表示风向, 但风向标不能动 & $0.3-1.5$ & $1-5$ \\
\hline 2 & 轻风 & 人面感觉有风, 树叶微响, 风向标能转动 & $1.6-3.3$ & $6-11$ \\
\hline 3 & 微风 & 树叶及微枝摇动不息, 㫋旗展开 & 3.4-5.4 & $12-19$ \\
\hline 4 & 和风 & 能吹起地面灰尘和纸张, 树的小枝摇动 & $5.5-7.9$ & $20-28$ \\
\hline 5 & 清劲风 & 有叶的小树摇摆, 内陆的水面有小波 & $8.0-10.7$ & $29-38$ \\
\hline 6 & 强风 & 大树枝摇动, 电线呼呼有声, 举伞困难 & $10.8-13.8$ & $39-49$ \\
\hline 7 & 疾风 & 全树摇动, 迎风步行感觉不便 & $13.9-17.1$ & $50-61$ \\
\hline 8 & 大风 & 微枝折毁, 人行向前感觉阻力甚大 & $17.2-20.7$ & $62-74$ \\
\hline 9 & 烈风 & 建筑物有小损（烟图顶部及平屋摇动） & $20.8-24.4$ & 75-88 \\
\hline 10 & 狂风 & 陆上少见, 见时可使树木拔起或使建筑物损坏严重 & $24.5-28.4$ & 89-102 \\
\hline 11 & 暴风 & 陆上很少见, 有则必有广泛损坏 & $28.5-32.6$ & $103-117$ \\
\hline 12 & 䫖风 & 陆上绝少见, 摧毁力极大 & $32.7-36.9$ & $118-133$ \\
\hline 13 & - & - & $37.0-41.4$ & $134-149$ \\
\hline 14 & - & - & $41.5-46.1$ & $150-166$ \\
\hline 15 & - & - & $46.2-50.9$ & $167-183$ \\
\hline 16 & - & - & $51.0-56.0$ & $184-201$ \\
\hline 17 & - & - & $56.1-61.2$ & $202-220$ \\
\hline
\end{tabular}

资料来源：国家标准GB/T 19201-2006 
表 2. 住宅破坏程度表

\begin{tabular}{|c|c|}
\hline 名称 & 破坏情况描述 \\
\hline 基本完好 & $\begin{array}{l}\text { 建筑物承重和非重承构件完好, 或个别非承重构件轻微损坏, 不加修理可继续使 } \\
\text { 用。 }\end{array}$ \\
\hline 轻微破坏 & $\begin{array}{l}\text { 个别承重构件出现可见裂缝, 非承重构件有明显裂缝, 不需要修理或稍加修理即可 } \\
\text { 继续使用。 }\end{array}$ \\
\hline 中等破坏 & $\begin{array}{l}\text { 多数承重构件出现轻微裂缝, 部分有明显裂缝, 个别非承重构件破坏严重, 需要一 } \\
\text { 般修复后可继续使用的。 }\end{array}$ \\
\hline 严重破坏 & 多数承重构件破坏较严重, 或有局部倒塌, 需要大修, 个别建筑修复困难。 \\
\hline 完全破坏 & 多数承重构件严重破坏, 结构濒于崩溃或已倒毁, 已无修复可能。 \\
\hline
\end{tabular}

\section{1 巨灾事件离散模型}

设在某地发生一次大于等于 $m_{1}$ 巨灾的条件下, 这次巨灾是 $m_{i}$ 级的概率是一个离散关系, 如表 3 所 示, 记为 $P_{1}\left(m_{i}\right)$ 。注意, $P_{1}\left(m_{i}\right)$ 是一个条件概率分 布，而不是某时段内发生 $m_{i}$ 级巨灾的概率分布。

表3. 发生 $m_{i}$ 级巨灾的概率分布 $P_{1}\left(m_{i}\right)$

\begin{tabular}{|l|l|l|l|l|l|l|}
\hline$m_{i}$ 级巨灾 & $m_{1}$ & $m_{2}$ & $\ldots$ & $m_{i}$ & $\ldots$ & $m_{n}$ \\
\hline 概率 $P_{1}\left(m_{i}\right)$ & $p_{1}$ & $p_{2}$ & $\ldots$ & $p_{i}$ & $\ldots$ & $p_{n}$ \\
\hline
\end{tabular}

再设某时段 $T$ 内出现 $m_{1}$ 级以上巨灾的次数为 $k$ 的 概率分布是一个离散关系, 如表4所示, 记为 $P_{2}(k)$ 。

表4. 时段 $T$ 内 $m_{1}$ 级以上巨灾发生 $k$ 次的概率分布 $P_{2}(k)$

\begin{tabular}{|l|l|l|l|l|l|l|l|}
\hline 时段 $T$ 内次数 $k$ & 0 & 1 & 2 & $\ldots$ & $k$ & $\ldots$ & $\mathrm{N}$ \\
\hline 发生概率 $P_{2}(k)$ & $f_{0}$ & $f_{1}$ & $f_{2}$ & $\ldots$ & $f_{k}$ & $\ldots$ & $f_{N}$ \\
\hline
\end{tabular}

\section{2 经济损失离散模型}

经济损失与不同巨灾下保险区划内单体标的破 坏比例有关。设 $m_{i}$ 级巨灾发生时, 破坏程度为 $d_{j}$ 的单 体标的在保险区划内所占比例为 $A_{i j}$ 。该离散关系可 以由表5示之。

由于该表不能直接反映单体标的因巨灾所蒙受 的经济损失状况。为此需要建立在不同破坏程度 下, 经济损失程度比矩阵, 它反映的是破坏程度为 $d_{j}$ 时, 从统计意义上来说, 单体标的经济损失的情 况。自然, 破坏程度越严重, 经济损失所占该单体 标的原有价值的比例就越大。我们将此程度比记为 $B_{j}$ 。该离散关系可以由表6示之。

表6反映的是破坏程度与经济损失程度的自然关 系。由于一次巨灾事件保险损失肯定小于或等于经 济损失, 况且, 保险赔偿金额需要考虑保险责任、
赔偿责任限制、免赔额等诸多因素, 所以, 保险精 算使用的，是在表 6 基础上结合保险实践给出的，我 们用表7表示单体标的保险损失程度。

表5. 巨灾中单体标的破坏比矩阵（\%)

\begin{tabular}{|c|c|c|c|c|c|c|}
\hline 巨灾 & $d_{1}$ & $d_{2}$ & $\ldots$ & $d_{j}$ & $\ldots$ & $d_{t}$ \\
\hline$m_{1}$ & $A_{11}$ & $A_{12}$ & $\ldots$ & $A_{1 j}$ & $\ldots$ & $A_{1 q}$ \\
\hline$m_{2}$ & $A_{21}$ & $A_{22}$ & $\ldots$ & $A_{2 j}$ & $\ldots$ & $A_{2 q}$ \\
\hline$\ldots$ & $\ldots$ & $\ldots$ & $\ldots$ & $\ldots$ & $\ldots$ & $\ldots$ \\
\hline$m_{i}$ & $A_{i 1}$ & $A_{i 2}$ & $\ldots$ & $A_{i j}$ & $\ldots$ & $A_{i q}$ \\
\hline$\ldots$ & $\ldots$ & $\ldots$ & $\ldots$ & $\ldots$ & $\ldots$ &.. \\
\hline$m_{n}$ & $A_{n 1}$ & $A_{n 2}$ & $\ldots$ & $A_{n j}$ & $\ldots$ & $A_{n q}$ \\
\hline
\end{tabular}

表6. 保险区划内巨灾经济损失程度矩阵表（\%)

\begin{tabular}{|l|l|l|l|l|l|l|}
\hline 破坏程度 & $d_{1}$ & $d_{2}$ & $\ldots$ & $d_{j}$ & $\ldots$ & $d_{q}$ \\
\hline 经济损失 & $B_{1}$ & $B_{2}$ &.. & $B_{\mathrm{j}}$ & $\ldots$ & $B_{q}$ \\
\hline
\end{tabular}

表7. 保险区划内单体标的保险损失程度矩阵表(\%)

\begin{tabular}{|l|l|l|l|l|l|l|l|}
\hline 破坏程度 & $d_{1}$ & $d_{2}$ & $\ldots$ & $d_{j}$ & $\ldots$ & $d_{q}$ & 破坏程度 \\
\hline 保险损失 & $C_{1}$ & $C_{2}$ & $\ldots$ & $C_{\mathrm{j}}$ & $\ldots$ & $C_{q}$ & 保险损失 \\
\hline
\end{tabular}

3.3 计算期望损失值的离散模型

假定发生了 $m_{i}$ 级巨灾, 则依表5知, 破坏程度为 $d_{j}$ 的单体标的在所有单体标的中将占 $A_{i j}$ 的比例。而由 表7知, 这种破坏程度的住宅, 会产生量值为 $C_{j}$ 的保 险损失比例。于是, $m_{i}$ 级巨灾产生 $d_{j}$ 破坏程度的保险 损失程度比为 $D_{i j}=A_{i j} \times C_{j}, m_{i}$ 级巨灾对所有单体标 
的可能造成的保险损失程度比 $D_{i}$ 由式 (12) 计算, 这些数值可构成表8所示的保险区划内单体标的巨灾 台风保险损失程度比矩阵。

$D_{i}=D_{i 1}+D_{i 2}+\cdots+D_{i j}+\cdots+D_{i q}, \quad i=1,2, \ldots, n$

表8. 保险区划内单体标的巨灾保险损失程度比 矩阵 $(\%)$

\begin{tabular}{|c|c|c|c|c|c|c|c|}
\hline 巨灾 & & & & & & & \\
\hline$m_{1}$ & $d_{1}$ & $d_{2}$ & $\ldots$ & $d_{j}$ & $\ldots$ & $d_{q}$ & $\begin{array}{c}\text { 合 } \\
\text { 计 }\end{array}$ \\
\hline$m_{2}$ & $D_{21}$ & $D_{22}$ & $\ldots$ & $D_{2 j}$ & $\ldots$ & $D_{2 q}$ & $D_{2}$ \\
\hline$\ldots$ & $\ldots$ & $\ldots$ & $\ldots$ & $\ldots$ & $\ldots$ &.. & \\
\hline$m_{i}$ & $D_{i 1}$ & $D_{i 2}$ & $\ldots$ & $D_{i j}$ & $\ldots$ & $D_{i q}$ & $D_{i}$ \\
\hline$\ldots$ & $\ldots$ & $\ldots$ & $\ldots$ & $\ldots$ & $\ldots$ & $\ldots$ & \\
\hline$m_{n}$ & $D_{n 1}$ & $D_{n 2}$ & $\ldots$ & $D_{n j}$ & $\ldots$ & $D_{n q}$ & $D_{n}$ \\
\hline
\end{tabular}

当 $m_{i}$ 级巨灾发生时, 假定其在保险区划内的影 响范围所占区划面积的比为 $S_{i}$, 则产生的保险损失 程度之比 $H_{i}$ 由式 (13) 计算。

$$
H_{i}=D_{i} \times S_{i}, \quad i=1,2, . ., n
$$

为简单起见, 我们用表 3 给出的概率分布, 依式 (14) 计算出时段 $T$ 内 $m_{1}$ 级以上巨灾发生的期望次数 $\bar{k}$ 作为各级巨灾的 $T$ 内发生次数使用, 即,

$$
\bar{k}=\sum_{k=1}^{N}(k-1) f_{k}=f_{2}+2 f_{3}+3 f_{4}+\cdots+(N-1) f_{N}
$$

按简单的累加原则, $m_{i}$ 级巨灾在年内给保险区 造成的保险损失程度之比可由式（15）计算。

$$
H_{i}^{(\bar{k})}=D_{i} \times S_{i} \times \bar{k}, \quad i=1,2, . ., n
$$

考虑 $m_{i}$ 级巨灾发生的概率, 依表 2 , 其 $T$ 内 $m_{i}$ 级 巨灾造成的保险损失率 $M_{i}$ 可由式（16）计算。

$$
M_{i}=p_{i} H_{i}^{(\bar{k})}
$$

于是, 根据随机变量期望值的定义, $T$ 时段内巨灾标 的保险期望损失率 $M$ 可由式 (17) 进行计算。

$$
M=\sum_{i=1}^{n} p_{i} H_{i}^{(\bar{k})}
$$

综合上面的相关计算结果, 我们可以得出保险 期望损失率测算表，如表9所示。

表9 保险区划内 $m_{1}$ 级以上巨灾 $T$ 时段内保险标的 期望损失率测算表 $(\%)$

\begin{tabular}{|c|l|c|c|c|c|c|}
\hline 序号 & 巨灾等级 & $m_{1}$ & $m_{2}$ & $\ldots$ & $m_{n}$ & 合计 \\
\hline 1 & 发生概率 & $p_{1}$ & $p_{2}$ & $\ldots$ & $p_{n}$ & 1 \\
\hline 2 & 损失程度比 & $D_{1}$ & $D_{2}$ & $\ldots$ & $D_{n}$ & $100 \%$ \\
\hline 3 & 影响区域 & $S_{1}$ & $S_{2}$ & $\ldots$ & $S_{n}$ & \\
\hline 4 & 期望次数 & $\bar{k}$ & $\bar{k}$ & $\ldots$ & $\bar{k}$ & \\
\hline 5 & 期望损失率 & $M_{1}$ & $M_{2}$ & $\ldots$ & $M_{n}$ & $M$ \\
\hline
\end{tabular}

由表3-表8和式 (12) - (17) 给出的模型就称为 巨灾保险期望损失离散模型（简称 “期望损失离散 模型” ), 表9中的最后一行数据, 就是这一该模型 计算出的结果。依此进行的巨灾保险费率的厘定, 则需根据保险业自身的许多实际情况进行考虑, 我 们将在下面的案例分析中加以讨论。

\section{4. 期望损失离散模型在精算中的应用}

本文将期望损失离散模型用于福建住宅台风保险 的精算，给出保险区划梯度费率表。

\section{1 研究区概述}

福建省位于中国东南沿海, 全省土地面积为 12.14 万平方千米，约占全国土地总面积的 $1.3 \%$ 。 境内峰岭等峙, 丘陵连绵, 河谷、盆地穿插其间, 山地、丘陵占全省总面积的 $80 \%$ 以上。

全省陆地海岸线总长 3000 多公里。由于靠近世 界上最大的台风源地, 福建省是中国台风灾害最严 重的省份之一。相关资料表明, 近 30 年来, 平均每 年有 1.5 个台风登陆福建，4 个台风影响福建，每 年造成近百人死亡和亿元的直接经济损失, 台风灾 害是福建所有自然灾害中危害最大、损失最严重的, 已经严重影响福建省经济可持续发展, 当地民众对 台风保险有较高的需求。

\section{2 福建住宅台风保险期望损失计算}

2009 年 6 月, 本文第二作者对福建省民政厅进 行了调研，并收集了 2007 和 2008 年两年台风住宅 损失的相关数据资料。为简化相关的计算, 我们作 如下相关假设:

（一）住宅标的的抗灾能力主要体现在其建筑物 的结构性能方面, 针对台风巨灾, 以抗灾能力的强 
度排列依次分为钢结构、钢混、砖混、砖木和木结 构。台风主要发生在我国东南沿海地区, 城乡差异 相对较小。在福建省, 地级城市市区住宅主要是砖 混结构和钢混结构，城镇和农村地区 $95 \%$ 以上住宅 是砖混结构, 两种结构有类似之处, 为简化说明应 用方法, 故以砖混结构代替所有住宅（福建省民政 厅所提供的资料也没有细分住宅结构），以下将单 体砖混结构住宅简称单体住宅;

（二）基于福建省绝大部分住宅在地级市和农村 地区，经验估计每套住房的平均价 30 万元;

（三）假设被保险人分担巨灾风险的比例为 $20 \%$ ，即保险人承担每套单体住宅 $80 \%$ 的经济损失。 每栋住宅都是足额办理承保手续的。

在财产保险精算中, 易损度是一个重要的概 念。针对巨灾风险, 我们给易损度的定义如下: 在 确定巨灾保险区划不同地域内，以确定的时间段

（通常最近三年），对某一巨灾风险每次事件所造
成某类保险标的的损失金额进行年度累计，然后与 该地域内的保险标的价值累计相比，所得的比值就 是巨灾保险区划内不同地域同类保险标的的年度风 险易损度。

按照易损度大小来划分风险的强度就是风险梯 度。在巨灾保险区划内不同地区的同类保险标的的 易损度所代表的风险强度构成了巨灾保险区划。

以住宅为保险对象, 以福建省各地级市为风险 梯度区域，根据所收集的 2007、2008 二年的台风住 宅损失相关数据资料，平均计算各地级市的台风住 宅易损度, 由大到小排列如下: 南平：0.007024, 三明：0.004702, 宁德：0.002323, 龙岩 : 0.000770 , 泉州: 0.000413 , 莆田: 0.000285, 福 州： 0.000262 , 漳州：0.000149, 厦门： 0.000056 。据此, 我们得到的福建住宅台风巨灾易 损度区划，见图 1。

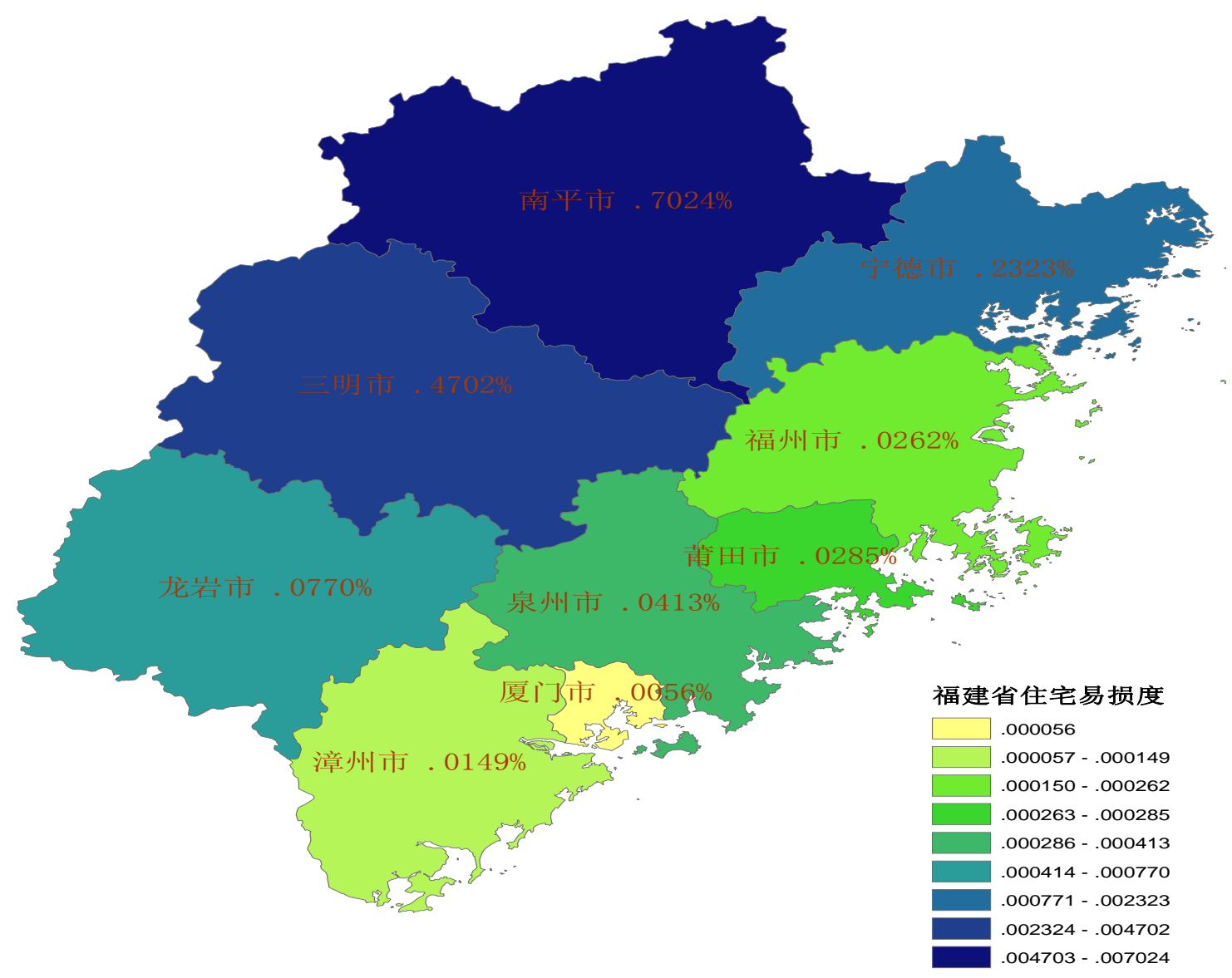

图 1 中国福建省住宅台风巨灾保险区划图 
根据 2001-2007 年的《热带气旋年鉴》, 在福建 住宅台风巨灾保险区划内, 我们计算出, 大于等于 9 级的台风中, 台风为 $w_{i}$ 级的频率分布为表 10 , 而 9 级以上台风出现不同次数的频率分布为表 11 。

表 10. 福建省 9 级以上台风不同等级发生频率的分 布情况

\begin{tabular}{|c|c|c|c|c|c|}
\hline 台风强度 $w_{i}$ & 9 & 10 & 11 & 12 & 12 级以上 \\
\hline 发生频率 & 0.3 & 0.35 & 0.25 & 0.09 & 0.01 \\
\hline
\end{tabular}

根据 2001-2007 年的《热带气旋年鉴》, 在福建 住宅台风巨灾保险区划内, 我们计算出, 大于等于 9 级的台风中, 台风为 $w_{i}$ 级的频率分布为表 10 , 而 9 级以上台风出现不同次数的频率分布为表 11 。

表 11 . 福建省一年内出现 9 级以上台风次数 $k$ 的频 率分布情况

\begin{tabular}{|c|c|c|c|c|c|c|c|c|}
\hline$k$ & 0 & 1 & 2 & 3 & 4 & 5 & 6 & $\geq 7$ \\
\hline 频率 & 0 & 0.07 & 0.35 & 0.39 & 0.12 & 0.06 & 0.01 & 0 \\
\hline
\end{tabular}

我们分别用表 10 和表 11 中的数值作为表 3 和表 4 中相应的概率估计值来使用。于是, 用式 (14) 可 计算出年内 9 级以上台风发生的期望次数 $\bar{k}$,

$$
\begin{aligned}
\bar{k}= & \sum_{k=1}^{8}(k-1) f_{k} \\
= & 0.07+2 \times 0.35+3 \times 0.39+4 \times 0.12 \\
& +5 \times 0.06+6 \times 0.01=2.78
\end{aligned}
$$

根据调研材料, 我们整理出福建省台风巨灾保 险区划内单体住宅巨灾台风破坏比矩阵表（表 12），以及福建省保险区划内巨灾台风经济损失程 度矩阵表 (表 13)，它们是期望损失离散模型中的
表 5 和表 6 的具体体现。表 12 反映了巨灾风险的不 同级别、损失破坏程度及其分布概率等因素, 某种 程度上也反映了单体住宅在不同的台风强度下的抗 灾能力。表 13 中的经济损失程度是指单体住宅遭受 巨灾风险后, 在不同破坏程度下, 可能的经济损失 占其整体价值之平均比例。例如, 由该表知, 在轻 微破坏情况下, 一个单体住宅将遭受的经济损失程 度为 $25 \%$ 。

保险赔偿金额需要考虑保险责任、赔偿责任限 制、免赔额等诸多因素, 涉及较多的主观判断, 很 难在保险损失与经济损失之间建立一个非常精准的 函数关系。然而, 根据经验数据, 我们假设自保比 例为 $20 \%$ 以上为, 从而可以统计一个平均线性比例 关系, 如果采用比例免赔额, 则存在一个比例关 系。为简化起见, 采用比例系数为 $r=20 \%$, 则可将 表 13 转化成表 14 的单体住宅的保险损失程度矩阵 表, 它是期望损失离散模型中表 7 的具体体现。例 如, 轻微破坏的保险损失程度是 $C_{2}=B_{2} \times r=25 \% \times 80$ $\%=20 \%$ 。

将表 12 的各项数据按行乘以表 14 的各项数 据, 即可得到单体住宅一次 9 级以上台风对住宅的 保险期望损失程度比矩阵, 如表 15 所示, 它是期望 损失离散模型中表 8 的在实例中的具体数值。

例如, 9级台风时, 轻微破坏的住宅, 会给保 险公司因这些住宅投保带来标的保险金额的损失比 为 $D_{12}=A_{12} \times C_{2}=0.12 \% \times 20 \%=0.0240 \%$ 。

根据台风的结构、能量和热带气旋风场的 “三 圈, 结构, 每个台风基本呈椭圆形形状。一般说 来, 从台风中心 (风眼) 至云墙 (眼壁) 的半径有 60 公里至 100 公里不等, 假设取中间值为 80 公

表 12. 福建省台风巨灾保险区划内单体住宅巨灾台风破坏比矩阵（\%)

\begin{tabular}{|c|c|c|c|c|c|c|}
\hline $\begin{array}{c}\text { 便坏 } \\
\text { 台风基本完好 }\end{array}$ & 轻微破坏 & 中等破坏 & 严重破坏 & 完全破坏 & 合计 \\
\hline 9 级 & $99.8 \%$ & $0.12 \%$ & $0.08 \%$ & $0 \%$ & $0 \%$ & $100 \%$ \\
\hline 10 级 & $99.617 \%$ & $0.342 \%$ & $0.0355 \%$ & $0.0053 \%$ & $0 \%$ & $100 \%$ \\
\hline 11 级 & $99.5331 \%$ & $0.3964 \%$ & $0.0468 \%$ & $0.0218 \%$ & $0.0019 \%$ & $100 \%$ \\
\hline 12 级 & $99.3975 \%$ & $0.5277 \%$ & $0.0559 \%$ & $0.0134 \%$ & $0.0055 \%$ & $100 \%$ \\
\hline 12 级以上 & $97.1069 \%$ & $1.8442 \%$ & $0.8475 \%$ & $0.1522 \%$ & $0.0492 \%$ & $100 \%$ \\
\hline
\end{tabular}


表 13. 福建省保险区划内巨灾台风经济损失程度矩阵表（\%)

\begin{tabular}{|c|c|c|c|c|c|}
\hline 破坏程度 & 基本完好 & 轻微破坏 & 中等破坏 & 严重破坏 & 完全破坏 \\
\hline 经济损失程度 & $0 \%$ & $25 \%$ & $55 \%$ & $85 \%$ & $95 \%$ \\
\hline
\end{tabular}

表 14. 福建省保险区划内单体住宅巨灾台风保险损失程度矩阵表（\%)

\begin{tabular}{|c|c|c|c|c|c|}
\hline 破坏程度 & 基本完好 & 轻微破坏 & 中等破坏 & 严重破坏 & 完全破坏 \\
\hline 保险损失程度 & $0 \%$ & $20 \%$ & $44 \%$ & $68 \%$ & $76 \%$ \\
\hline
\end{tabular}

表 15. 福建保险区划内单体住宅巨灾台风保险损失程度比矩阵（\%)

\begin{tabular}{|c|c|c|c|c|c|c|}
\hline 台风损坏 & 基本完好 & 轻微破坏 & 中等破坏 & 严重破坏 & 完全破坏 & 合计 \\
\hline 9 级 & $0 \%$ & $0.0240 \%$ & $0.0352 \%$ & $0 \%$ & $0 \%$ & $0.0592 \%$ \\
\hline 10 级 & $0 \%$ & $0.0684 \%$ & $0.0156 \%$ & $0.0036 \%$ & $0 \%$ & $0.0876 \%$ \\
\hline 11 级 & $0 \%$ & $0.0793 \%$ & $0.0206 \%$ & $0.0148 \%$ & $0.0014 \%$ & $0.1161 \%$ \\
\hline 12 级 & $0 \%$ & $0.1055 \%$ & $0.0246 \%$ & $0.0091 \%$ & $0.0042 \%$ & $0.1434 \%$ \\
\hline 12 级以上 & $0 \%$ & $0.3688 \%$ & $0.3729 \%$ & $0.1053 \%$ & $0.0374 \%$ & $0.8826 \%$ \\
\hline
\end{tabular}

里。虽然台风影响的范围方圆直径约为 1000 公里左 右, 但根据历史数据, 在这个椭圆形半径为 80 公里 的环带内, 暴风和暴雨强度最大, 对地面财产和人 员造成大面积、大范围、大量保险标的重大损失和 伤亡可能性最高, 对其他地方的影响是较小的。假 设台风在福建中部登陆, 由东南向西北移动, 横穿 整个福建省, 且以台风中心所作的四个象限内都遭 遇大风暴雨, 那么我们可以将其近似看作一个宽 160 公里, 长 480 公里（福建东西最大间距约 480 公里）的长方形。则一次 9 级以上台风, 在上述移 动路径下, 对福建最为完整的、且最大范围的破坏 性台风灾害所致的遭灾面积为 7.68 万平方公里, 约 占福建省陆地面积 12.4 万平方公里的 $61.93 \%$ （由 于考虑的是巨灾台风对住宅的影响, 故只考虑陆地 面积）。

巨灾保险区划一般较大, 不同的巨灾风险、触 发的强度、发生位置、次生灾害、影响时间等因 素, 对整个巨灾保险区划内的保险标的影响范围和 程度差异是较大的。就福建住宅台风巨灾保险区划 来说, 一个巨灾台风也不可能对福建整个保险区划 都有破坏性影响, 其影响范围和程度主要看生成时 间（是否与大潮汛、月盈月亏）、登陆地点、台风
强度、发展过程、行进路线、移动速度、影响时间 等因素来决定。如 2008 年的海鸥台风虽然达到 10 级, 且在福建霞浦县长春镇登陆, 但仅仅掠过福建 的北部（非常临近浙江的南部地区），随后就移向 东海, 影响路径和事件十分短暂, 所以该台风对福 建的影响的范围很微小。

基于以上分析, 我们只能凭经验假设一次 9 级 以上台风对福建住宅台风巨灾保险区划的平均影响 范围取中间值为 $30 \%$, 即, 表 9 中的 $S_{i}$ 均取值为 30 $\%$ 。

使用式（13）-（15）和表 10, 表 15 提供的 数据, 以及上面给出的 $\bar{k}$ 值和平均影响范围取中间 值 $S_{i}$, 我可以得到表 16 所示的保险期望损失率测算 表。

例如, 9 级台风时期望损失率计算出下:

$$
\begin{aligned}
M_{1} & =p_{1} H_{1}^{(\bar{k})} \\
& =p_{1} \times D_{1} \times S_{1} \times \bar{k} \\
& =0.3 \times 0.0592 \% \times 30 \% \times 2.78 \\
& =0.0148 \%
\end{aligned}
$$

4.3 费率计算公式 
表 16. 福建省住宅台风巨灾保险区划内 9 级以上台风年度保险期望损失率测算表（\%)

\begin{tabular}{|c|l|c|c|c|c|c|c|}
\hline 序号 & 台风等级 & 9 & 10 & 11 & 12 & 12 级以上 & 合计 \\
\hline$(1)$ & 发生概率 & 0.3 & 0.35 & 0.25 & 0.09 & 0.01 & 1 \\
\hline$(2)$ & 损失程度比 & $0.0592 \%$ & $0.0876 \%$ & $0.1161 \%$ & $0.1434 \%$ & $0.8826 \%$ & $100 \%$ \\
\hline$(3)$ & 影响区域 & $30 \%$ & $30 \%$ & $30 \%$ & $30 \%$ & $30 \%$ & \\
\hline$(4)$ & 期望次数 & 2.78 & 2.78 & 2.78 & 2.78 & 2.78 & \\
\hline$(5)$ & 期望损失率 & $0.0148 \%$ & $0.0256 \%$ & $0.0242 \%$ & $0.0108 \%$ & $0.0074 \%$ & $0.0827 \%$ \\
\hline
\end{tabular}

\section{I. 保额统计}

保额统计有两种方法, 一是在巨灾保险区划内 对每一住宅一一统计加总, 二是按照抽样统计, 得 出一套住宅平均价, 以此计算。显然第二种方法较 好。巨灾保险因实施强制保险, 所以统计在内所有 住宅必须参加保险。我们使用 2007 年和 2008 年福 建省统计年鉴, 经研究和整理, 得福建省住宅保额 统计如表 17 。

表 17. 福建台风巨灾保险区划内各地区保额统计表

\begin{tabular}{|c|c|c|c|}
\hline 地区 & $\begin{array}{c}\text { 户数 } \\
\text { (万户 })\end{array}$ & $\begin{array}{c}\text { 单价 } \\
\text { (万元 })\end{array}$ & $\begin{array}{c}\text { 价值 } \\
\text { (亿元 })\end{array}$ \\
\hline 福州 & 195 & 30.00 & $5,850.00$ \\
\hline 厦门 & 47 & 30.00 & $1,410.00$ \\
\hline 宁德 & 94 & 30.00 & $2,820.00$ \\
\hline 萳田 & 89 & 30.00 & $2,670.00$ \\
\hline 泉州 & 177 & 30.00 & $5,310.00$ \\
\hline 漳州 & 128 & 30.00 & $3,840.00$ \\
\hline 龙岩 & 82 & 30.00 & $2,460.00$ \\
\hline 三明 & 75 & 30.00 & $2,250.00$ \\
\hline 南平 & 87 & 30.00 & $2,610.00$ \\
\hline 合计 & 974 & 30.00 & $29,220.00$ \\
\hline
\end{tabular}

II. 费率调整因子的假定

根据巨灾保险费率组成和巨灾保险费率精算模 型, 结合巨灾保险的特点和保险公司一般的营运成 本经验数据，我们假设运营成本附加因子为 $20 \%$;
被保险人因参与风险分担, 自保 $20 \%$, 且设有免赔 额, 故其防灾防损意识加强, 应该设置诱导性费 率, 我们假设费率折扣因子为 $5 \%$; 安全性附加因 子纯粹是一个主观的经验假设, 为 $10 \%$ 。具体费率 调整因子假设如表 18 所示。

表 18. 福建住宅台风巨灾保险费率调整因子表

\begin{tabular}{|c|c|c|c|}
\hline $\begin{array}{c}\text { 调整因 } \\
\text { 子名称 }\end{array}$ & $\begin{array}{c}\text { 运营成本 } \\
\text { 附加因子 }\end{array}$ & $\begin{array}{c}\text { 安全性附 } \\
\text { 加因子 }\end{array}$ & $\begin{array}{c}\text { 费率折 } \\
\text { 扣因子 }\end{array}$ \\
\hline $\begin{array}{c}\text { 调整比 } \\
\text { 值 }\end{array}$ & $20.0 \%$ & $10.0 \%$ & $5.0 \%$ \\
\hline
\end{tabular}

III. 保险区划内不同区域的梯度费率系数

在一个巨灾保险区划内的所有地区所遭受侵袭 和影响的台风次数应该是均等的, 但是不同地区的 灾害风险强度是不一的, 可以设定一个地级市为一 个风险梯度。根据相关资料, 为简化说明, 这里不 妨将风险强度差不多的地级市归并为一个风险梯度 地区，合并为 4 个。考虑漳州的实际情况和两年数 据资料的局限性，对此作了调整。于是，我们得到 福建省的风险梯度划分如表 19, 假设福建省台风住 宅易损度最低的福州和厦门地区为 1 , 那么按照易 损度的数值, 简单算术平均推算出各地的实际梯度 费率系数。

表 19. 福建住宅台风巨灾保险区划内风险梯度系数

\begin{tabular}{|c|c|c|}
\hline 所属范围 (代码) & 梯度系数 & $\begin{array}{c}\text { 保额 } \\
\text { (亿元) }\end{array}$ \\
\hline 福州、厦门 (T1) & 1 & 7,260 \\
\hline 泉州、漳州、萳田 (T2) & 1.7736 & 11,820 \\
\hline 龙岩、宁德 (T3) & 9.7233 & 5,280 \\
\hline 南平、三明 (T4) & 36.8742 & 4,860 \\
\hline
\end{tabular}


IV．费率计算公式

\section{（1）巨灾保险费率的构成}

巨灾保险费率由基本费、梯度费率和安全费率 构成。

基本费率又称纯风险基准费率。世界上没有统 一的标准。美国将百年一遇的洪水作为基准洪水。 根据我国社会经济变化转快的特点, 以 3-5 年历史 数据统计所得的平均易损度为我国巨灾风险的基本 费率较为合适。

梯度费率反映的是不同地区所面临某类巨灾风 险的平均强度。巨灾保险区划内不同地区所面临的 同一巨灾风险的强度是不一的, 梯度费率可根据经 验数据, 诸如灾害风险强度、灾损率或以上述平均 易损度来确定。

不同地区的实际费率是在基本费率的基础上 乘以梯度费率系数而得。

在计算巨灾保险费率时考虑一定的安全系数, 涉及的费率称为安全费率, 其与保险标的本身的抗 灾能力、区域防灾工程规划等密切相关。安全费率 的出现, 使巨灾保险费率的精算有别于商业保险费 率精算。

\section{(2) 调整系数}

经营成本和相关税收数:由于巨灾保险的公共产 品属性, 具有一定的公益性, 所以商业的逐利性要 少考虑 ${ }^{[2]}$ 。巨灾保险主要经营成本是代办费用、管 理费用、公估费用等, 或者一定的微利。日本地震 保险费率也不考虑承保人盈利, 这反映了地震保险 的公益本质。

折扣系数:保险人对以下四种情况给予被保险人 一定的折扣系数, 一是为了鼓励防灾防损, 保险人 设计具有诱导性的防灾防损差别费率。二是如果有 新的防灾防损设施投入使用, 在新的保险年度厘定 费率时就要对折扣系数加以调整。三是国家关于建 筑规范、抗灾级别的提高而设置的折扣系数。有的 国家还设有建筑年限折扣系数等。总折扣系数一般 在 $10 \%$ 以内浮动。

\section{（3）费率调整因子}

根据前述巨灾保险费率的构成和调整系数易 知, 建立巨灾保险费率精算模型需要设立如下调整 因子:

运营成本附加因子：设第 $i$ 种巨灾保险保险人的 运营管理成本（包括管理费用、佣金、税费等）比 率为 $\theta_{i, 1}$ 。
安全性附加因子：设第 $i$ 种巨灾保险保险人的风 险波动安全和自然灾害风险发展趋势增强等因素的 附加率为 $\theta_{i, 2}$ 。

折扣因子: 根据前述费率折扣系数所考虑的因 素, 设第 $i$ 种巨灾保险的实际费率折扣系数为 $\theta_{i, 3}$ 。

梯度因子：设第 $i$ 种巨灾保险在整个保险区划内 一年的基本费率为 $\alpha_{i}$, 设第 $i$ 种巨灾保险在地点 $L_{i, j}$ 内一年的区域费率为 $\alpha_{i, j}$, 设第 $i$ 种巨灾保险在地点 $L_{i, j}$ 的梯度费率系数为 $t_{i, j}$, 即

$$
\alpha_{i, j}=\alpha_{i} \times t_{i, j}
$$

（4）保险金额

在给定的保险区划内，我们根据民政部门、公 安局部门、邮政编码、投保单等相关数据资料, 可 以轻而易举地统计得到在整个保险区划内各个保险 标的保险金额的合计，假设为 $B_{i, j}$ 。

（5）计算公式

根据巨灾保险期望损失的一般模型（公式

(9) ) 考虑上述的调整因子和调整系数, 可得第 $i$ 种巨灾保险平均费率的一般通用精算模型:

$$
\begin{aligned}
\alpha_{i}= & \frac{E_{i}}{\left(\sum_{j} B_{i, j} \times t_{i, j}\right) \times\left(1+\theta_{i, 3}\right) \times\left(1-\theta_{i, 1}-\theta_{i, 2}\right)} \\
= & \frac{\sum_{j}\left(\lambda_{i, j} \times \int_{\Omega_{i, j}} H_{i}\left(x, S_{i, j}, M_{i, j}, D_{i, j}, I_{i, j}\right) \times p_{i, j}(x) d x\right)}{\left(\sum_{j} B_{i, j} \times t_{i, j}\right) \times\left(1+\theta_{i, 3}\right) \times\left(1-\theta_{i, 1}-\theta_{i, 2}\right)}
\end{aligned}
$$

\section{4 费率计算演示}

在本例中, 费率计算公式具体化为:

$$
\begin{aligned}
\alpha & =\frac{E}{\left(\sum_{1 \leq j \leq m} Q_{j} \times t_{j}\right) \times\left(1+\theta_{3}\right) \times\left(1-\theta_{1}-\theta_{2}\right)} \\
& =\frac{\left(\sum_{1 \leq j \leq m} Q_{j}\right) \times M}{\left(\sum_{1 \leq j \leq m} Q_{j} \times t_{j}\right) \times\left(1+\theta_{3}\right) \times\left(1-\theta_{1}-\theta_{2}\right)}
\end{aligned}
$$

（1）纯风险平均费率计算

根据式（20）、表 16、18 和 19，可以得到巨 灾保险的纯风险平均费率 (即风险梯度 $\mathrm{T} 1$, 参照系 数为 1 的地区住宅台风巨灾保险费率），具体计算 如下:

分子 $=E($ 总损失 $)$ 
$=$ 总计保额 $\times 9$ 级以上台风年度保险期望损失率

$=(7,260+11,820+5,280+4,860) \times 0.0827 \%$

$=24.16494$ ( 亿元 $)$

分母 $=\left(\sum\right.$ 保额 $\times$ 梯度系数 $) \times(1+$ 费率折扣因子 $)$

$\times$ (1-运营成本附加因子-安全性附加因子)

$=(7,260 \times 1+11,820 \times 1.7736+5,280 \times 9.7233$

$+4,860 \times 36.8742) \times(1+5.0 \%)$

$\times(1-20.0 \%-10.0 \%)$

$=190,197.1$ (亿元)

综上, 得:

纯风险平均费率 $=24.16494 \div 190197.1=0.0127 \%$

（2）梯度纯风险费率计算

根据梯度费率定义, 见式 (18), 我们计算出 各风险梯度区域的标准费率, 如表 20 所示。

表 20 福建住宅台风巨灾保险区划梯度纯风险费率 测算表

\begin{tabular}{|c|c|c|c|}
\hline $\begin{array}{c}\text { 风险 } \\
\text { 梯度 }\end{array}$ & 所属范围 & $\begin{array}{c}\text { 实际梯 } \\
\text { 度系数 }\end{array}$ & $\begin{array}{c}\text { 梯度纯 } \\
\text { 风险费率 }\end{array}$ \\
\hline 1 & 福州、厦门 & 1 & $0.0127 \%$ \\
\hline 2 & 泉州、漳州、萳田 & 1.7736 & $0.0225 \%$ \\
\hline 3 & 龙岩、宁德 & 9.7233 & $0.1235 \%$ \\
\hline 4 & 南平、三明 & 36.8742 & $0.4683 \%$ \\
\hline
\end{tabular}

(3) 梯度标准费率计算

根据以上测算，南平和三明地区一套价值为 30 万保额的单体住宅将缴纳 $1,404.9$ 元保费 (300, 000 $\times 0.4683 \%$ ），而在福州、厦门地区一套 30 万住宅 的保费为 38.1 元, 一套 80 万的住宅, 缴纳保费为 101.6 元, 如果一套价值为 200 万元的住宅, 缴纳 保费为 254 元, 对比说明两者差距是很大的。这就 印证了前述风险越高的地区, 往往是农村地区, 购 买力较弱, 超出普通老百姓的承受能力, 将给巨灾 保险方案的实施带来很多不良影响。基于前述的巨 灾保险准共产品属性及其在费率精算中的体现, 有 必要对梯度纯风险费率进行调整, 具体方法有二:

第一，基于实际梯度系数，结合上述考虑，我 们需要重新主观选定梯度系数, 计算调整后的梯度 标准费率, 这一费率也是对外公布的承保费率。如 表 21 所示。

表 20 与表 21 对比, 风险梯度 1 与 4 的费率差 距由原先的 36.87 倍, 缩小至 6 倍。保费支出得到了 有效均衡。
表 21 福建住宅台风巨灾保险区划梯度费率表

\begin{tabular}{|c|c|c|c|c|}
\hline $\begin{array}{l}\text { 风险 } \\
\text { 梯度 }\end{array}$ & 所属范围 & $\begin{array}{l}\text { 实际梯 } \\
\text { 度系数 }\end{array}$ & $\begin{array}{l}\text { 选定梯 } \\
\text { 度系数 }\end{array}$ & $\begin{array}{l}\text { 梯度标 } \\
\text { 准费率 }\end{array}$ \\
\hline 1 & 福州、厦门 & 1 & 1 & $0.0446 \%$ \\
\hline 2 & $\begin{array}{c}\text { 泉州、漳州、 } \\
\text { 蒪田 } \\
\end{array}$ & 1.7736 & 1.5 & $0.0669 \%$ \\
\hline 3 & 龙岩、宁德 & 9.7233 & 3 & $0.1338 \%$ \\
\hline 4 & 南平、三明 & 36. 8742 & 6 & $0.2676 \%$ \\
\hline
\end{tabular}

第二, 对龙岩、宁德、南平和三明等农村地 区，可根据物价指数，消费水平和人均收入，政府 对被强制要求购买住宅台风保险的被保险人, 实行 财政补贴、所得税退税或营业税减免等措施，以提 高消费者的购买能力, 从而降低被保险人购买巨灾 保险所支付的保费, 达到相对于购买群体消费能力 能承受的程度。这样被保险人实际支付的保费还会 下降。如何优惠, 主要由巨灾保险制度决定。

基于上述数据资料和应用方法所计算的福建住 宅台风巨灾保险费率，对被保险人来说应该是完全 可以接受的, 对巨灾保险共同体来说, 也能够建立 巨灾保险基金，这两方面说明费率测算是切合实际 的。

\section{5. 结论与讨论}

由于中国社会发展很快，相适应的巨灾保险资 料并不多, 国外大型保险公司和机构开发的巨灾保 险模型很难在中国投入使用。从理论上讲，巨灾保 险费率精算并不难, 但精算的精度不仅在于模型自 身的完备性，更在于模型的可用性和相关数据资料 是否能够支持这样的模型。显然, 一个既能支持精 算，又能得数据资料支持的模型成为在中国进行巨 灾保险费率精算的首选。本文建议的离散模型, 有 效使用时间系列不长的相关资料实现了对福建省台 风巨灾保险费率的精算。经福建省一些资深保险专 家的经验判断, 认为给出的结果较为可靠。

\section{参考文献}

[1] 石兴, 自然灾害风险可保性理论及其应用研究, 北京师 范大学博士学位论文, 2009。

S. Xing, Insurability Study and its Application on Natural Disasters, PhD thesis, Beijing Normal University, 2009.

[2] 张兆本, 公共经济学, 北京: 人民出版社, 2005

Z. B. Zhang, Public Economics, Beijing: The People's Press, 2005 